\title{
MODEL IDENTIFICATION AND LEVEL CONTROL OF COUPLED TANKS SYSTEM
}

\author{
OKUBANJO AYODEJI ${ }^{* 1}$, OKANDEJI ALEXANDER ${ }^{2}$, ALAO PETER ${ }^{1}$ \\ OLALUWOYE OLAWALE ${ }^{1}$, ONAIFO FRANK ${ }^{1}$, MUFUTAU OLAYEMI ${ }^{3}$ \\ ${ }^{1}$ Department of Electrical and Electronics Engineering, Olabisi Onabanjo University, \\ Ago-Iwoye, 2002, Nigeria. \\ ${ }^{2}$ Department of Electrical and Electronics Engineering, University of Lagos, Akoka, \\ Nigeria \\ ${ }^{3}$ Department of Electrical and Electronics Engineering, DS Adegbenro ICT Polytechnic, \\ Itori-Ewekoro, Nigeria
}

\begin{abstract}
The Couple Tank (CT) system remains as a benchmark to investigate and test new emerging control schemes in the process industry since its dynamic emulates many factual system in the field of process control. In this paper, we examine the performance evaluation of two control algorithms, proportional derivative controller (PD) and proportional-integralderivative controller (PID). The dynamics of the CT system is experimentally derived by system identification method and validated with a mathematical model that depicts the dynamic behaviour of the coupled tank system. Furthermore, the control schemes are expanded on the model obtained through system identification method. The simulation results showed that the PD controller did not meet all the specified control objectives. To improve the response an integral controller was incorporated to the PD controller and the response was compared to that of the PID controller and uncompensated system. The results revealed that the PID controller satisfied all the control goals. However, the PD controller was more satisfactory in terms of time response criteria.
\end{abstract}

Keywords: PID Controller, Coupled-tank, Water level control, System identification, PID turning method.

\section{INTRODUCTION}

Coupled tank (CT) system is a classical non-linear control whose control goals are to design controllers that will maintain the liquid level at the desired level (set-point) irrespective of parameter variation. Controlling the level of a liquid in such tank is crucial from safety point of view because the tanks are so coupled together that level interact and deviation in the set point may upset the equilibrium of the reaction with the potential consequence of spillage of hazardous material and wastage of valuable plant assets. Couple Tank has received a considerable attention over decades in process industry because of its unique dominant dynamic characteristics of non-linearity and non-minimum phase behaviour. This dynamic emulates many factual systems in the field of process control and it has been established as a benchmark to investigate and test new emerging control algorithms in process industry. With the growing trend of process automation, the process industry has witnessed the evolution of new

\footnotetext{
* Corresponding author, email: okubanjo.ayodeji@oouagoiwoye.edu.ng

(C) 2020 Alma Mater Publishing House
} 
and more challenging applications that not only enhanced process safety but also revolutionized industries such as petrochemical, waste water treatment, biochemical, food beverages, refinery, metallurgical and pharmaceutical etc. [1 - 3]. So, several control algorithms have been proposed, implemented and adopted over the past few decades and the quest for new development of CT control still continues. Smart controller based on reinforcement learning algorithm in [1], linear machine inequality (LMI) tuned PI controller in [4], neural network based predictive controller in conjunction with PID controller in [5] which is further extended with simplified additive autoregressive exogenous models in [6], LabVIEW based PID controller in [7], Simulink-PLC based level control in [8], tuned PID controller in [9]. In In the work of [2] the performance of model predictive, MPC,PI and PI-plusfeedforward controllers are compared and the performance of MPC are more acceptable in terms of disturbance handling and time response criteria. Furthermore, in [10], the effectiveness of fuzzy logic controller,FLC and conventional PID controller are examined. The simulation result shown that FLC is superior to PID in terms of transient response. This is further extended to non-linear two conical tank system in [11]. Nagammai \& Latha, [12], proposed full state feedback (FSFB) controller, linear quadratic controller (LQR) with pre-compensator for three tank system. The transient response characteristic and performance index indicated the efficacy of FSFB controller over LQR. Recently [13], proposed a cascade control to handle flow rate of water in level system. The novelty of the proposed algorithm lie on the error minimization at optimum level and faster rate of settling time. [14], presented a mathematical model of two tank interacting system and proposed hybrid PID and Fuzzy logic based controller. Although, the response of the PID controller to unit step is relatively slow with considerably overshoot and to optimize the peak overshoot a fuzzy controller was integrated into the model.

\section{EXPERIMENTAL SETUP}

\subsection{Material and Methods}

An experimental modeling method known as system identification is used to estimate the model from the measurement of input and output. The dynamics of the process are analyzed within the threshold of the linear region since the system is Non- linear Time Invariant models. Three different models are experimental estimated from the steady state, step response and bode plot. In the steady state model, the output is measured over an input from 0 to 10 volts at steps of 0.5 volt and the output data are obtained to determine the model. Table 1 presented the input-output data with corresponding point operation. To ascertain that the model depicts the system dynamic, we take step responses from the point of operation as indicate in Figure 1.

Two step responses are measured, one for the positive step and another one for negative step in a step size is $20 \%$ of the linear control range and the model transfer function is obtained. However, this only give a rough indication of the first dominant dynamics, therefore, a second measurement, bode plot (Table 2 and 3), is taken to make the model more accurate and search for other higher order dynamics in the process. Furthermore, the Bode diagram is measured around the point of operation and a sine wave with small amplitude within the linear control range is used as input $\mathrm{u}(\mathrm{t})$ of the process. As the process is assumed linear, the output $\mathrm{y}(\mathrm{t})$ again would be a sinewave, with the same frequency, but possibly with a different amplitude and phase. The data in Table 2 shown the experimental frequency and the corresponding derived parameters. The model is further validated through a mathematical model.

Table 1. Input-Output Measured Data.

\begin{tabular}{|c|l|l|l|l|l|l|l|l|l|l|l|l|l|l|l|l|l|l|l|}
\hline $\begin{array}{c}\text { Input } \\
\text { Voltage }\end{array}$ & 0.5 & 1.0 & 1.5 & 2.0 & 2.5 & 3.0 & 3.5 & 4.0 & 4.5 & 5.0 & 5.5 & 6.0 & 6.5 & 7.0 & 8.0 & 8.5 & 9.0 & 9.5 & 10.0 \\
\hline $\begin{array}{c}\text { Output } \\
\text { Voltage }\end{array}$ & 0.0 & 0.0 & 0.0 & 0.0 & 0.0 & 0.0 & 0.0 & 0.0 & 3.10 & 5.63 & 8.68 & 8.79 & 9.08 & 9.18 & 9.58 & 9.62 & 9.68 & 9.68 & 9.68 \\
\hline
\end{tabular}

Table 2. Bode Plot Measurement.

\begin{tabular}{|c|c|c|c|c|c|c|c|c|}
\hline $\begin{array}{c}\text { Frequency, } \omega \\
{[\mathrm{RAD} / \mathrm{s}] \text { or }[\mathrm{Hz}]}\end{array}$ & $\begin{array}{c}\text { Amplitude } \\
\boldsymbol{A}_{\text {in }},[-]\end{array}$ & $\begin{array}{c}\text { Amplitude } \\
\boldsymbol{A}_{\text {out }},[-]\end{array}$ & $\begin{array}{c}\text { Cycle } \\
\text { time } \\
\boldsymbol{t}_{\text {cycle }},[\mathrm{s}]\end{array}$ & $\begin{array}{c}\text { Shift } \\
\Delta t,[\mathrm{~s}]\end{array}$ & $\begin{array}{c}\text { True freq. } \\
\Omega, \\
{[\mathrm{RAD} / \mathrm{s}]} \\
\text { or }[\mathrm{Hz}]\end{array}$ & $\begin{array}{c}\text { Gain } \\
K(\omega),[-]\end{array}$ & $\begin{array}{c}\text { Gain } \\
\mathrm{K}(\omega), \\
{[\mathrm{dB}]}\end{array}$ & $\begin{array}{c}\text { Phase } \\
\boldsymbol{\varphi}(\boldsymbol{\omega}), \\
{[\mathrm{RAD}] \text { or }} \\
{\left[^{\circ}\right]}\end{array}$ \\
\hline 0.01 & 0.5 & 1.5360 & 299.55 & 1.1 & 0.01 & 3.072 & 9.748 & -1.322 \\
\hline 0.02 & 0.5 & 1.0680 & 212 & 46.7 & 0.02 & 2.136 & 6.592 & -79.30 \\
\hline 0.05 & 0.5 & 0.5920 & 125.65 & 27.7 & 0.05 & 1.184 & 1.467 & -79.36 \\
\hline 0.06 & 0.5 & 0.4060 & 107.85 & 24.4 & 0.06 & 0.812 & -1.808 & -81.45 \\
\hline 0.07 & 0.5 & 0.3040 & 94.45 & 22.3 & 0.07 & 0.608 & -4.322 & -85.00 \\
\hline 0.08 & 0.5 & 0.2400 & 79.88 & 20.0 & 0.08 & 0.480 & -6.375 & -90.50 \\
\hline
\end{tabular}


More so, the magnitude plot further indicated that the model is a second order system without delay and at $\omega=0.02$, the slope of the curve is $-20 \mathrm{~dB} / \mathrm{decade}$ and there is pole at $\omega=0.02$. Similarly, at $\omega=0.05$, the slope of the curve changes from $-20 \mathrm{~dB} /$ decade to $-40 \mathrm{~dB} /$ decade and there is a pole at $\omega=0.05$ with a dc gain of 3.07 as evaluated from Figure 4.
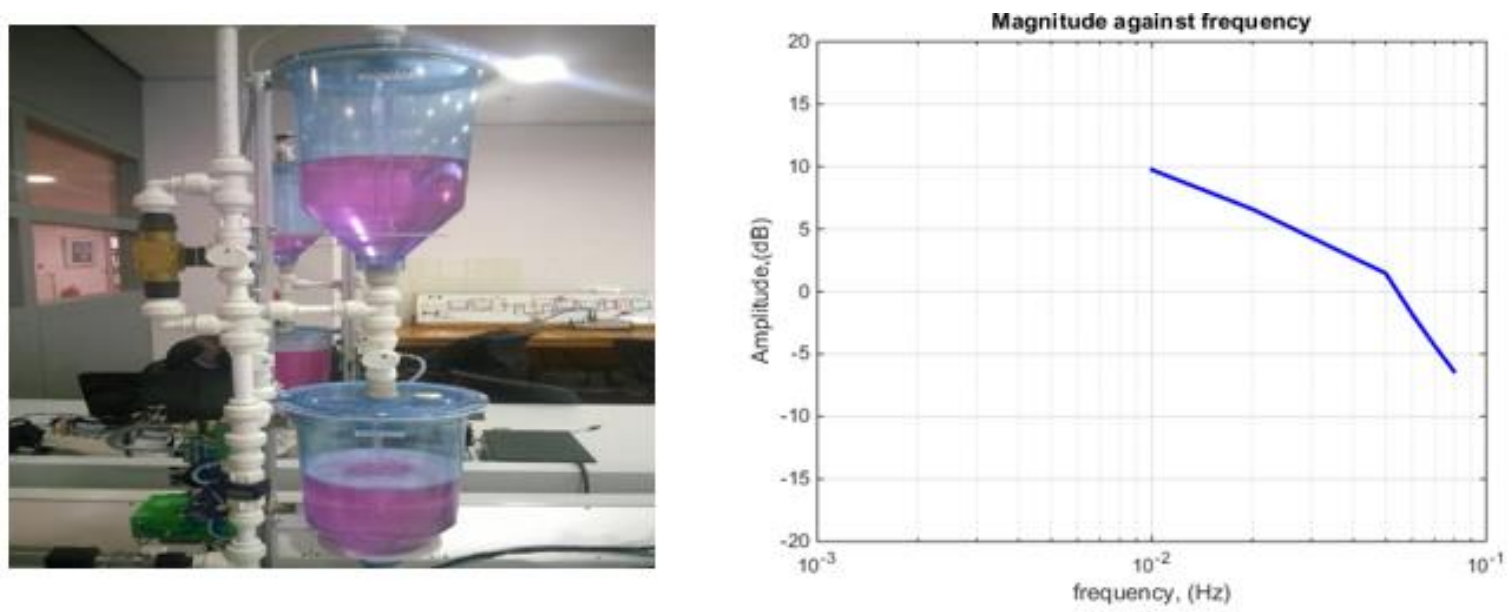

Fig. 1. (a) Experimental Set-up of Coupled Tank System (b) Magnitude plot.

Table 3. Estimated Linear models.

\begin{tabular}{|l|l|c|c|}
\hline Model & Point of Operation & Transfer, Function, $\boldsymbol{H}(\boldsymbol{s})$ & \multicolumn{1}{c|}{$\begin{array}{c}\text { Model } \\
\text { Order }\end{array}$} \\
\hline Steady State & Linear range & $H(s)=K_{D_{C}}$ & - \\
\hline Step Response & Linear range & $H(s)=\frac{0.04}{s+0.0074}$ & $1^{\text {st }}$ \\
\hline Bode plot & Linear range & $H(s)=\frac{0.00307}{(s+0.02)[s+0.05)]}$ & $2^{\text {nd }}$ \\
\hline Mathematical & linear & $H(s)=\frac{h_{2}(s)}{F_{i}(s)}$ & $2^{\text {nd }}$ \\
& & $=\frac{R_{2}}{A_{1} R_{1} A_{2} R_{2} S^{2}+\left(A_{1} R_{1}+R_{2} A_{1}+A_{2} R_{2}\right) S+1}$ & \\
\hline
\end{tabular}

\subsubsection{Mathematical Model}

Figure 1 presented as a schematic diagram of the coupled tanks system in which $F_{i}$, is the fluid's input, $F_{1}$ and $F_{2}$ the exit flows, $A_{1}$ and $A_{2}$ the cross-sectional area of the tank base, $h_{1}$ and $h_{2}$ the fluid's level. $R_{1}$ and $R_{2}$ the hydraulic resistances. The mathematical model determining, in dynamic regime based on mass balance for the tank 1 and tank 2 are given as:

$$
\left\{\begin{array}{l}
\frac{d h_{1}}{d t}=\frac{1}{A_{1}}\left(F_{i}-F_{1}\right) \\
\frac{d h_{2}}{d t}=\frac{1}{A_{2}}\left(F_{1}-F_{2}\right)
\end{array}\right.
$$

Considering:

$$
F_{1}=\frac{h_{1}-h_{2}}{R_{1}} ; F_{2}=\frac{h_{2}}{R_{2}}
$$


It results:

$$
\begin{gathered}
\left\{\begin{array}{l}
\frac{d h_{1}}{d t}=\frac{h_{1}}{A_{1} R_{1}}+\frac{h_{2}}{A_{1} R_{1}}+\frac{F_{i}}{A_{1}} \\
\frac{d h_{2}}{d t}=\frac{h_{1}}{A_{2} R_{1}}-\frac{R_{1}+R_{2}}{A_{2} R_{1} R_{2}} h_{2}
\end{array}\right. \\
{\left[\frac{d h_{1}}{d t}\right]=\left[\begin{array}{ll}
\frac{-1}{A_{1} R_{1}} & \frac{1}{A_{1} R_{1}} \\
\frac{1}{A_{2} R_{1}} & \frac{-\left(R_{1}+R_{2}\right.}{A_{2} R_{1} R_{2}}
\end{array}\right]\left[\begin{array}{l}
h_{1} \\
h_{2}
\end{array}\right]+\left[\begin{array}{c}
\frac{1}{A_{1}} \\
0
\end{array}\right] F_{i}} \\
y=\left[\begin{array}{ll}
1 & 0 \\
0 & 1
\end{array}\right]\left[\begin{array}{l}
h_{1} \\
h_{2}
\end{array}\right]
\end{gathered}
$$

The relationship (4) and (5) represent the SIMO mathematical model of the system of a coupled tanks, in general form

$$
\begin{aligned}
& x=A x+B u \\
& y=C x+D u
\end{aligned}
$$

The process from Figure 2 may be presented a SIMO system, with one input and two output and based on the relationship input-state-output (ISO)-input-output (IO):

$$
H(s)=C(s I-A)^{-1}+B+D
$$

This expression is used to obtained the transfer function as a function of the fluid's level $h_{1}$ and $h_{2}$, but we are interested in the transfer function $H_{F(s)}$ for the CT system from pump to tank 2. Hence,

$$
H_{F}(s)=\frac{h_{2}}{F_{i}}=\frac{R_{2}}{A_{1} R_{1} A_{2} R_{2} s^{2}+\left(A_{1} R_{1}+A_{1} R_{2}+A_{2} R_{2}\right) s+1}
$$

is obtained from the mathematical relation in equation 7. Also, by substituting the values of the CT system parameters and the constant given by Table 4, the transfer function for the CT system is given by equation 9 .

$$
\frac{h_{2}}{F_{i}}=\frac{0.0016}{s^{2}+0.07 s+0.003}
$$

Table 4. Parameters of the CT system.

\begin{tabular}{|c|c|c|}
\hline Parameter & Value & Units \\
\hline$A_{1}$ & 250 & $\mathrm{C} / \mathrm{m}^{2}$ \\
\hline$A_{2}$ & 200 & $\mathrm{C} / \mathrm{m}^{2}$ \\
\hline$R_{1}$ & 0.01 & $\mathrm{Cm}^{2} / \mathrm{sec}$ \\
\hline$R_{2}$ & 0.01 & $\mathrm{Cm}^{2} / \mathrm{sec}$ \\
\hline
\end{tabular}




\section{RESULTS AND DISCUSSION}

Two different control algorithms are implemented on the CT system to effectively control the liquid level and also the model dynamic of the coupled tank system are compared. The control schemes includes the proportionalderivative controller (PD) and the proportional-integral-derivative controller. These control schemes depend on the performance criteria such as settling time, steady state error, maximum overshoot etc. In this design, we want to ensure that the system fulfill the following system requirement specifications:

- Stable;

- $\quad$ Robust: Phase Margin (PM) better than $45^{\circ}$ and Gain Margin (GM) better than $6 \mathrm{~dB}$;

- $\quad$ Steady state error should be zero;

- $\quad$ Overshoot should be less than $4.3 \%$;

- $\quad$ Settling time for $10 \%$; as fast as possible.

There is need to evaluate the performance of the uncompensated system to determine how much improvement in transient response is required. Based on the system requirements, the transfer model obtained from bode diagram is analysed by SISOTOOL and Matlab script as given below in order to find out the controller that best match the system specification requirement.

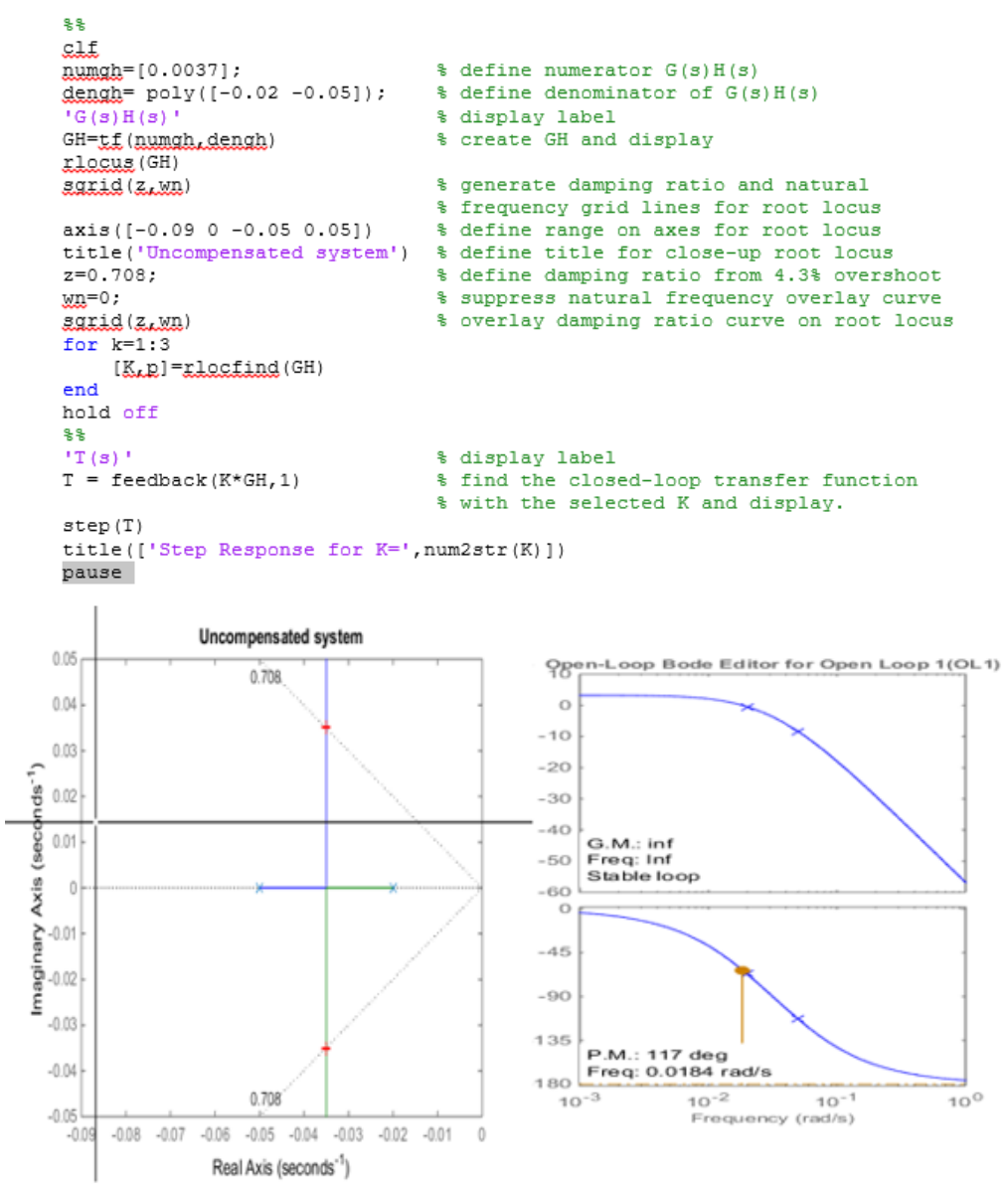

Fig. 2. Root locus and bode plot for uncompensated system. 


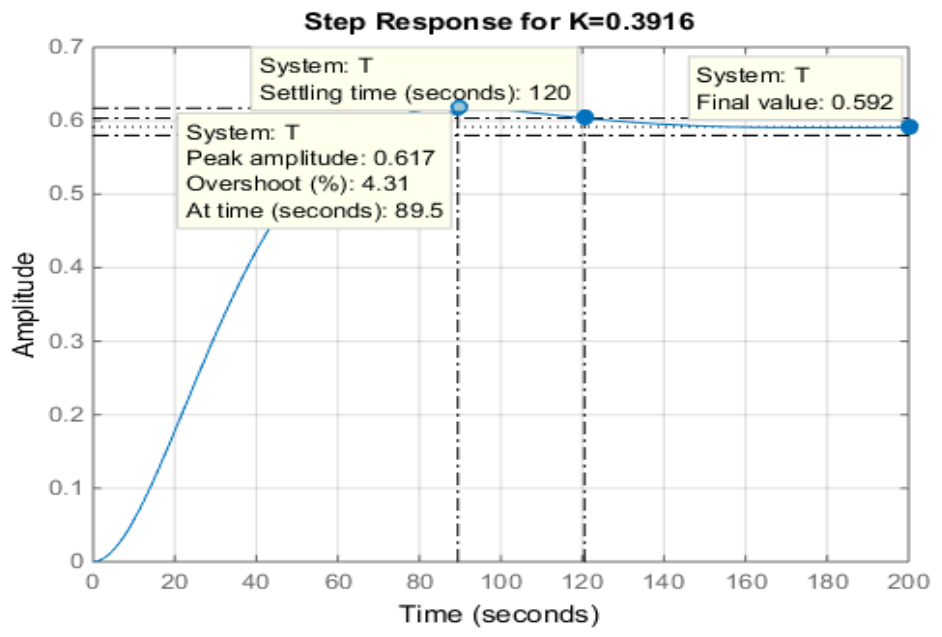

Fig. 3. Step response of the uncompensated system.

Table 5. Predicted characteristics of uncompensated system.

\begin{tabular}{|c|c|c|c|c|c|c|c|c|c|}
\hline $\begin{array}{c}\text { Plant and } \\
\text { compensator }\end{array}$ & $\begin{array}{c}\text { Dominant } \\
\text { poles }\end{array}$ & $\begin{array}{c}\text { Gain } \\
\mathbf{K}\end{array}$ & $\zeta$ & $\boldsymbol{\omega}_{\boldsymbol{n}}$ & $\boldsymbol{\%}$ OS & $\boldsymbol{T}_{\boldsymbol{s}}$ & $\boldsymbol{T}_{\boldsymbol{p}}$ & $\boldsymbol{K}_{\boldsymbol{p}}$ & $\boldsymbol{e}(\infty)$ \\
\hline $0.0037 * K$ & $\begin{array}{c}-0.035 \\
\pm 0.035 i\end{array}$ & 0.3916 & 0.708 & 0.049 & 4.3 & 114 & 89.75 & 1.448 & 0.408 \\
\hline$(s+0.02)(s+0.05)$ & $\underline{0.035}$ & & & & & & & \\
\hline
\end{tabular}

The first step is to search along the $4.3 \%$ overshoot line $(\zeta=0.708)$ with the Matlab script presented above, and the dominant poles is found at $-0.035 \pm 0.035 i$ with a gain $\mathrm{K}$ of 0.3916 . However, when compared the calculated value to those obtained from the simulation, it is revealed that the uncompensated system (Table 5) have a steady state error of 0.405 , settling time of 120 secs and stable system as indicated in Figure 3 with the corresponding step response in Figure 4. To further speed up the response of the system in order to meet the requirement (settling time as fast as $10 \%$ ) a PD controller is implemented with SISOTOOL. The dynamics behaviour of the CT system is determined by its closed loop poles position, so that the complex dominant poles is $-0.26 \pm 0.26 i$ with a damping ratio of $4.3 \%$ and predicted characteristics of compensated-PD System is shown in Table 6 with the corresponding system response as shown in Figure 5.

Table 6. Predicted characteristics of compensated-PD system.

\begin{tabular}{|c|c|c|c|c|c|c|c|c|c|}
\hline Plant and compensator & Dominant poles & $\begin{array}{c}\text { Gain } \\
\text { K }\end{array}$ & $\zeta$ & $\boldsymbol{\omega}_{\boldsymbol{n}}$ & $\boldsymbol{\%}$ OS & $\boldsymbol{T}_{\boldsymbol{s}}$ & $\boldsymbol{T}_{\boldsymbol{p}}$ & $\boldsymbol{K}_{\boldsymbol{p}}$ & $\boldsymbol{e}(\infty)$ \\
\hline$\frac{0.0037 * K(s+0.05)}{(s+0.02)(s+0.05)(s+0.5)}$ & $-0.26 \pm 0.26 i$ & 33.79 & $\begin{array}{l}0.70 \\
8\end{array}$ & 0.368 & 4.3 & 7.23 & 12.08 & 12.50 & 0.074 \\
\hline
\end{tabular}

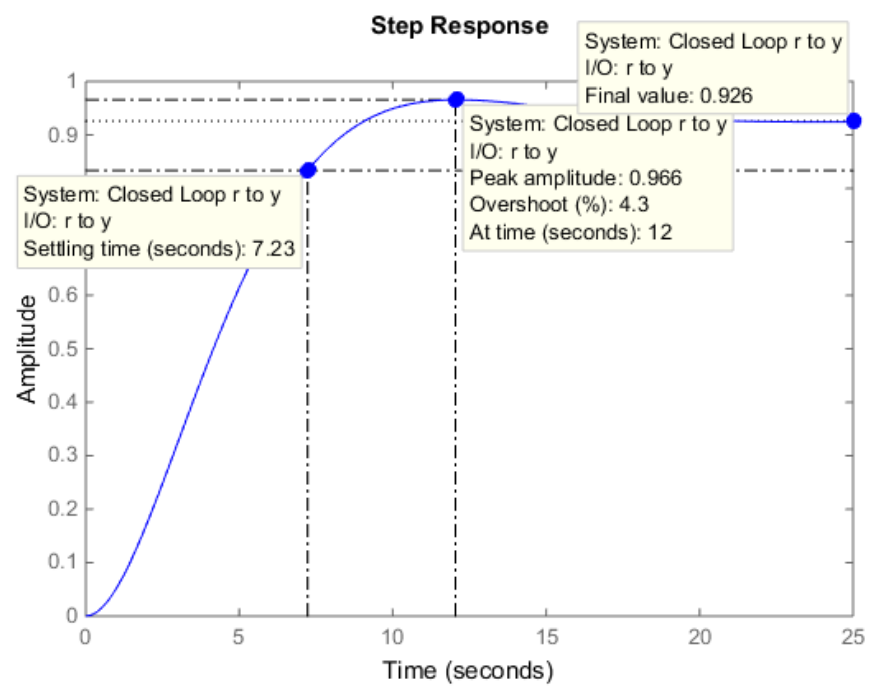

Fig. 4. Effect of PD controller on the CT model. 
Figure 5 revealed that there is a significant reduction in the settling time as a result of the compensated dominant closed loop poles have more negative real part than the uncompensated system which resulted in shorter settling time and the steady state error improved by one-fifth that of uncompensated system however, the PD- compensated system could not reduce the error to zero as stated in the requirement. Also, the compensated system is stable infinity gain margin with a corresponding phase margin of $70.6^{\circ}$ which is better than $45^{\circ}$. Although, PD controller improved the transient response by decreasing the settling time but has minute improvement on the steady state error. Furthermore, it can be noticed that the PD turning did not give us a PD controller that satisfies zero steady state error. Hence, to ensure that a zero steady state error is achieved a PID controller is implemented such that the transient response of the PD controller is not in any affected. From the simulation results shown in Figure 6 it can be concluded that PID controller eliminates the offset of the proportional derivative mode and still provides fast response. The PID controller scheme satisfies zero steady error, $7.5 \mathrm{sec}$ settling as fast as $10 \%$, stable system with a gain margin at infinity, phase margin of $65.5^{\circ}$ better than $45^{\circ}$ as specified in the requirement and $4.3 \%$ percentage overshoot.

Based on the results presented in Figure 6, an improvement was observed after an integral controller was added to the PD controller. It can also be deduced that the PID exhibits better response and performance than PD controller (Table 7). Figure 7, 8, 9, and 10 show the response of the output on the hands on CT system at HAN university of Applied Sciences in the laboratory with corresponding increase in the step point. Similarly, Figures 10, 11 and 12 show the implementation of the controller's parameters on the hands on coupled tank system. The Simulation results further revealed that the PID scheme has the affinity to enhance the robustness, transient and steady performance than the PD controller. The performance of the PID controller after proper tuning of the controller parameters for $\mathrm{K}_{\mathrm{p}}=18.6, \mathrm{~K}_{\mathrm{i}}=59.25, \mathrm{~K}_{\mathrm{d}}=20$.

Table 7. Performance characteristics of the uncompensated system, PD controller and PID controller.

\begin{tabular}{|c|l|l|l|l|l|l|l|l|l|}
\hline Plant and Controller & $\begin{array}{l}\text { Dominant } \\
\text { poles }\end{array}$ & $\begin{array}{l}\text { Gain } \\
\mathrm{K}\end{array}$ & $\zeta$ & $\omega_{n}$ & $\% \mathrm{OS}$ & $T_{s}$ & $T_{p}$ & $K_{p}$ & $e(\infty)$ \\
\hline $0.0037 * K$ & $-0.035 \pm 0.035 i$ & 0.3916 & 0.708 & 0.049 & 4.3 & 114 & 89.75 & 1.448 & 0.408 \\
\hline $\begin{array}{c}(s+0.02)(s+0.05) \\
\text { Plant and PD controller }\end{array}$ & $\begin{array}{l}\text { Dominant } \\
\text { poles }\end{array}$ & $\begin{array}{l}\text { Gain } \\
\mathrm{K}\end{array}$ & $\zeta$ & $\omega_{n}$ & $\% \mathrm{OS}$ & $T_{s}$ & $T_{p}$ & $K_{p}$ & $e(\infty)$ \\
\hline$\frac{0.0037 * K(s+0.05)}{(s+0.02)(s+0.05)(s+0.5)}$ & $-0.26 \pm 0.26 i$ & 33.79 & 0.708 & 0.368 & 4.3 & 7.23 & 12.08 & 12.50 & 0.074 \\
\hline Plant and PID controller & Dominant poles & $\begin{array}{l}\text { Gain } \\
\mathrm{K}\end{array}$ & $\zeta$ & $\omega_{n}$ & $\% \mathrm{OS}$ & $T_{s}$ & $T_{p}$ & $K_{p}$ & $e(\infty)$ \\
\hline$\frac{0.0037 * K(s+0.05)(s+0.199)}{s(s+0.02)(s+0.05)(s+0.5)}$ & $-0.25 \pm 0.25 i$ & 33.823 & 0.708 & 0.354 & 4.3 & 7.5 & 12.57 & 2.490 & 0.0 \\
\hline
\end{tabular}

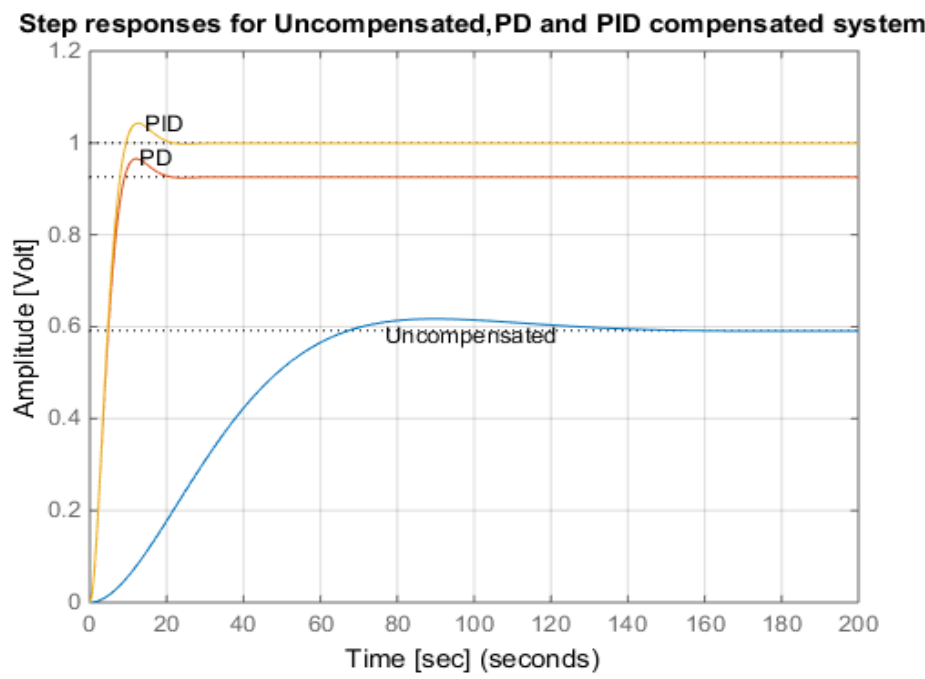

Fig. 5. Performance evaluation of the plant, PD controller and PID controller. 

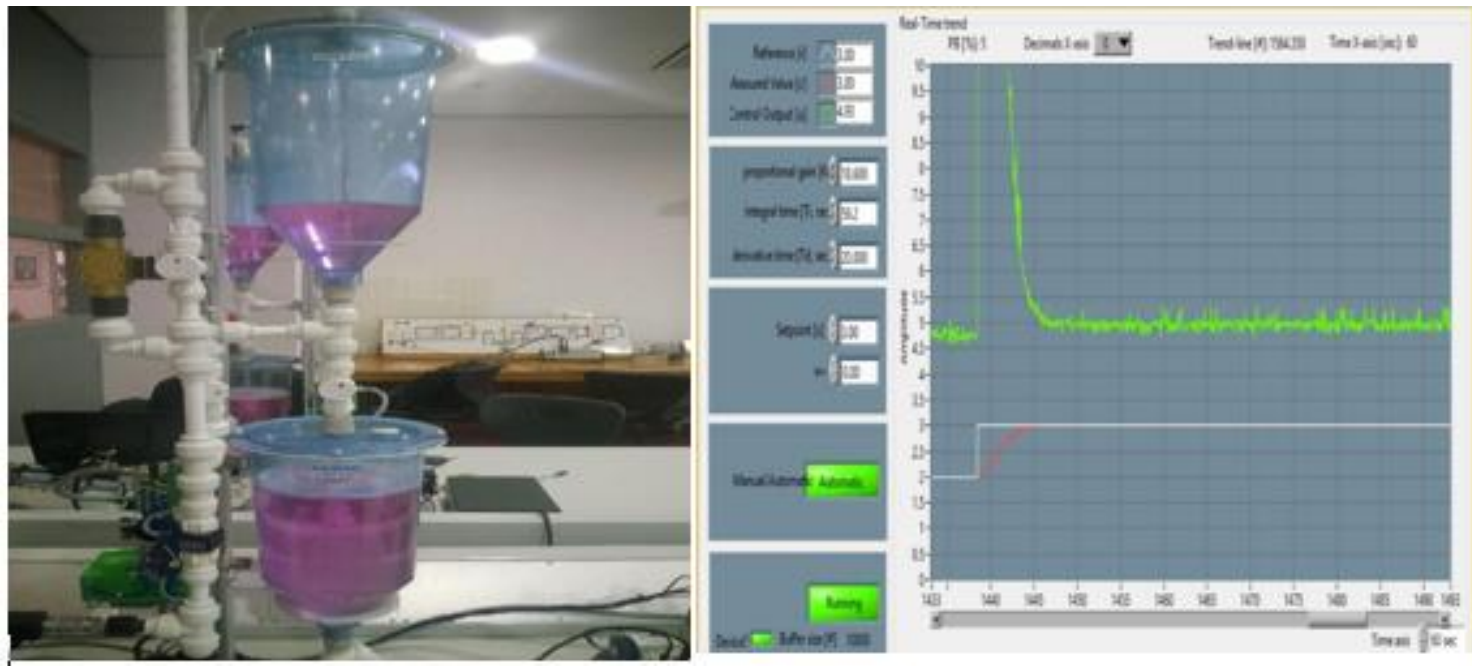

Fig. 6. Set point equal to 1 .
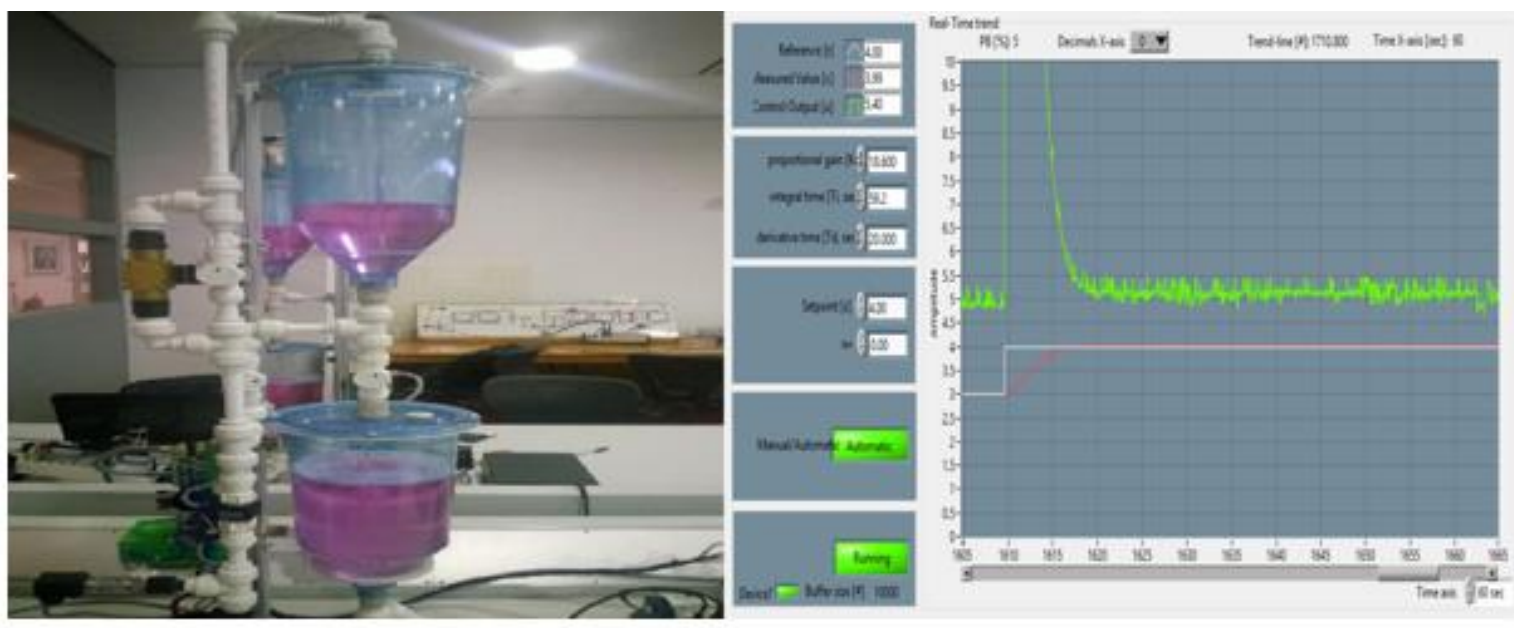

Fig. 7. Set point equal to 2.
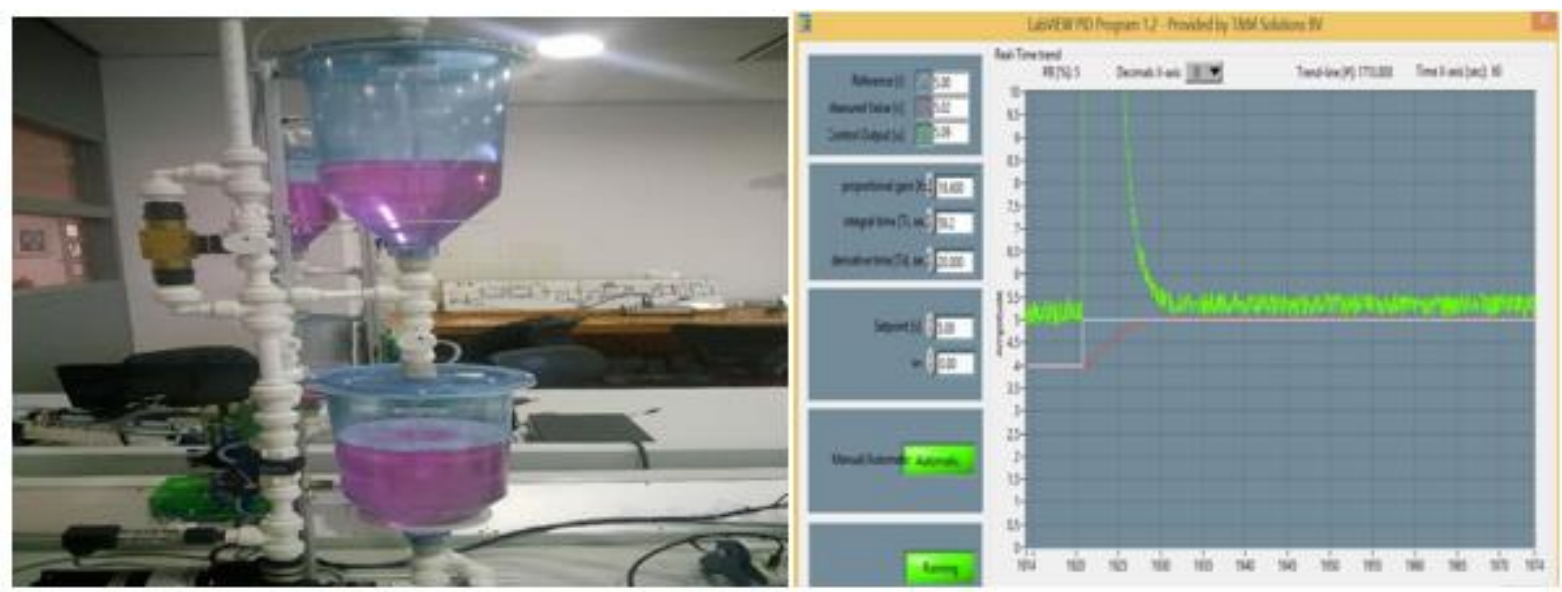

Fig. 8. Set point equal to 3 . 

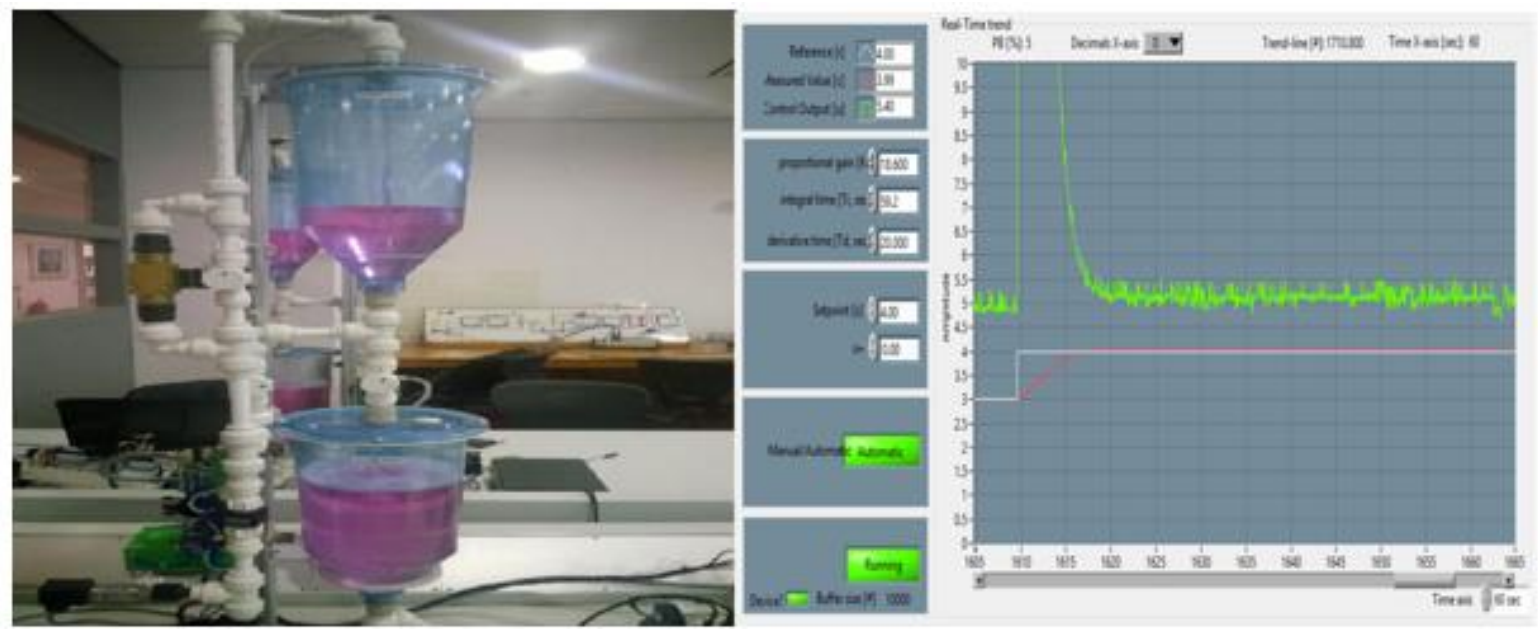

Fig. 9. Set point equal to 4 .
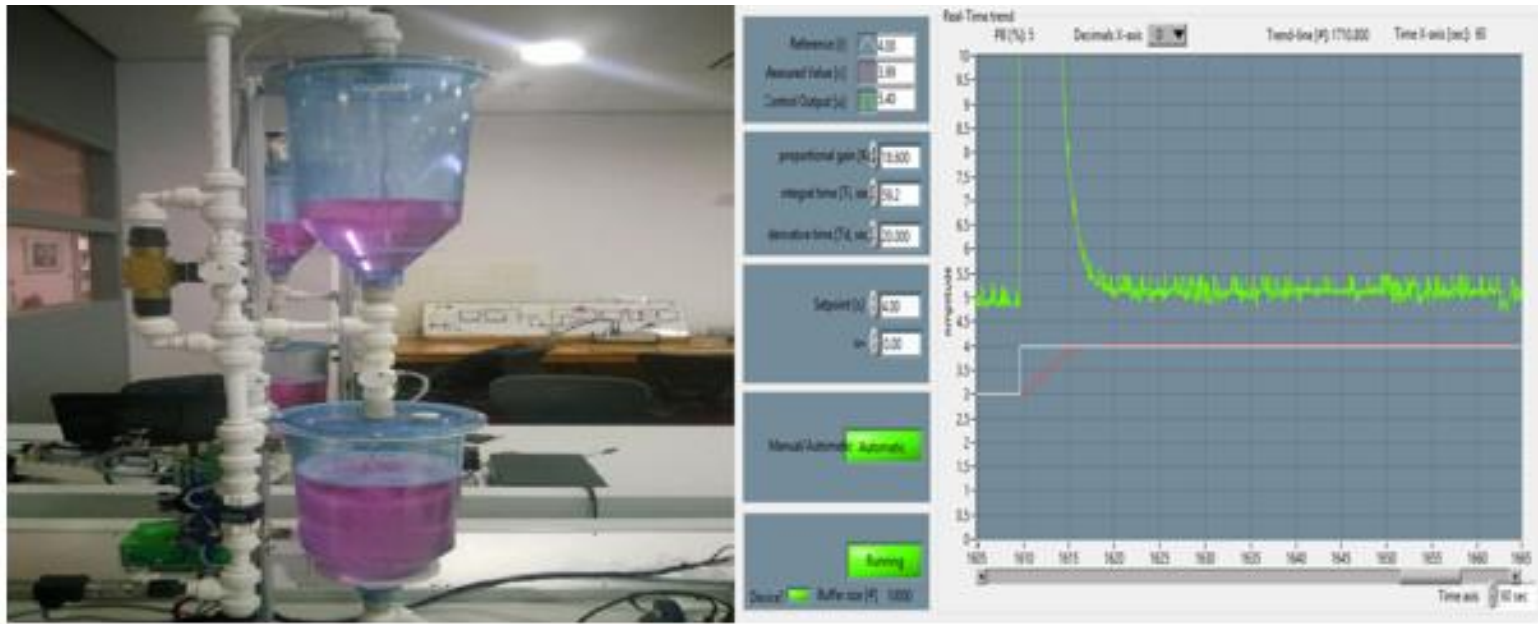

Fig. 10. Set point equal to 5 .
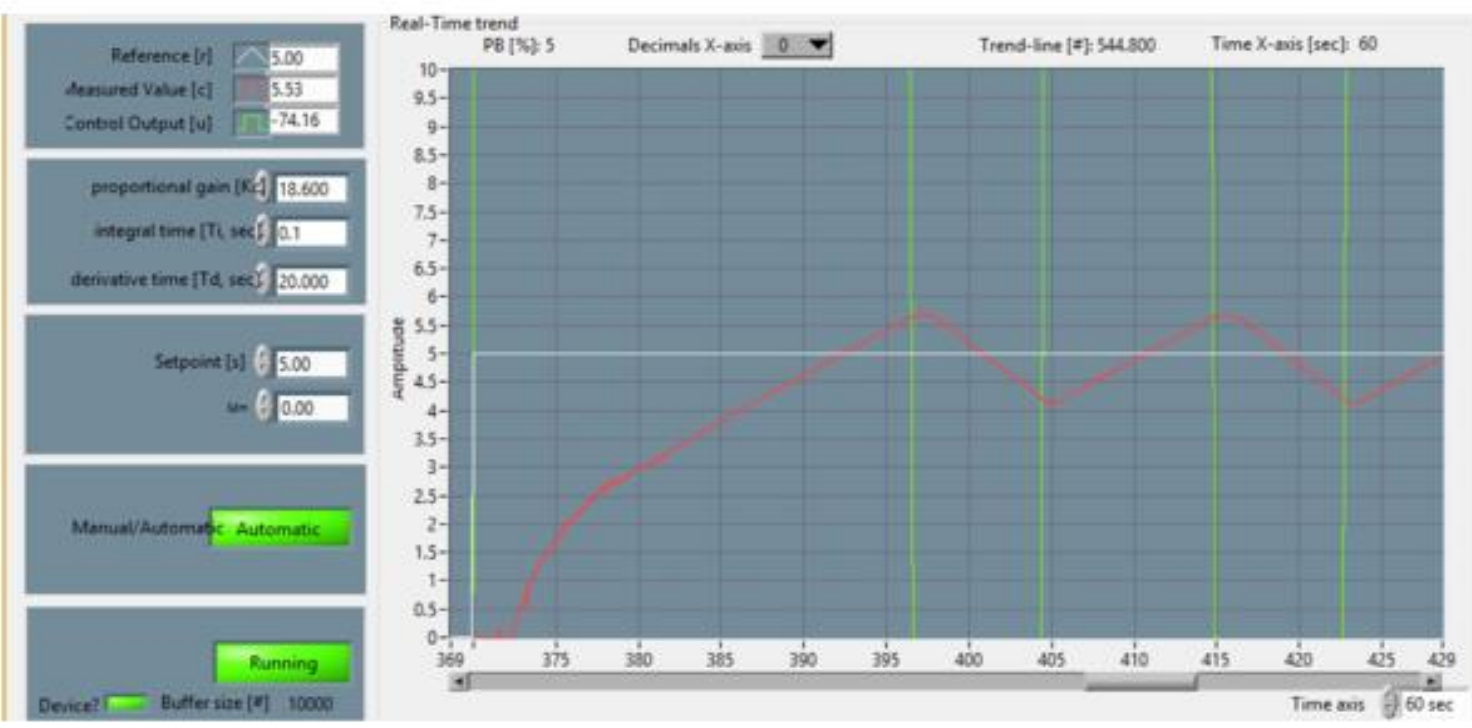

Fig. 11. Implementation of PD Controller on the physical CT system. 


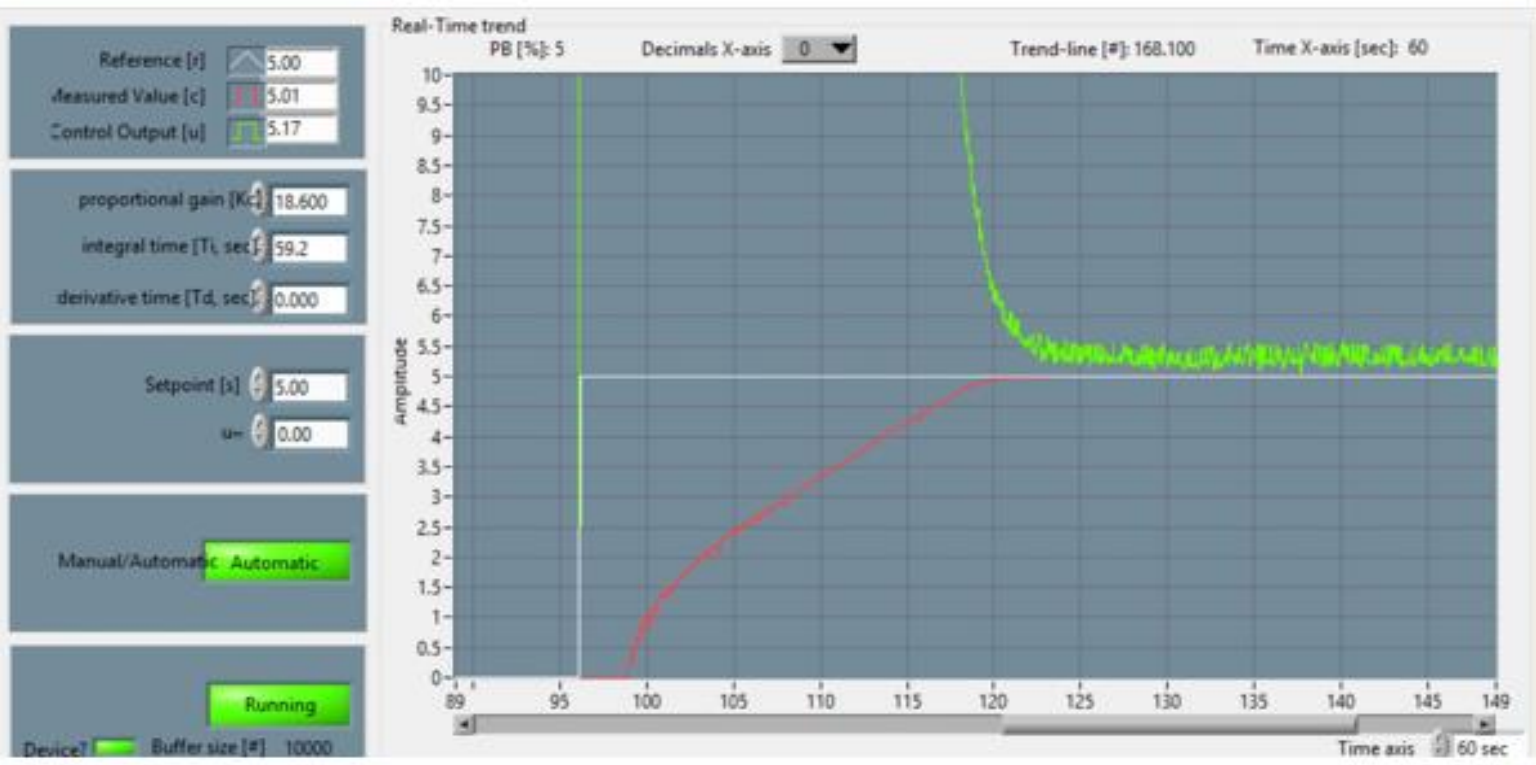

Fig. 12. Implementation of PD Controller on the physical CT system.

\section{CONCLUSIONS}

The dynamic model and control algorithms designed of a coupled tank system have been successfully formulated and implemented in this paper. The CT dynamic model was anatomized based on analytical and empirical approach and to simulate the dynamics accurately, the coupled tank model is obtained through system identification and validated with a mathematical model such that the system is within the neighborhood of the linear region. Hence, two control algorithms are implemented with MATLAB/Simulink environment on the model to investigate the performance characteristics of the CTS. The PD controller was unable to satisfy all the control objectives. To further improve the robustness of the integral controller was incorporated to the PD controller. The response for the PID controller was compared to the response obtained by PD for level control in tank. It was observed that, the PID controller and PID controller can be used to achieve all the control objectives. However, the response by PID controller was more acceptable in terms of time response characteristics where $4.3 \%$ overshot and zero steady state were recorded. Furthermore, PID control scheme gives a better response and performance. This relative performance investigation for this baseline system substantiates that the proposed PID controller is simple, effective and robust for controlling linearized model of dynamic coupled tank system.

\section{REFERENCES}

[1] Ramanathan, P., Mangla, K.K., Satpathy, S., Smart controller for conical tank system using reinforcement learning algorithm, Measuremet: Journal of International Measurement Confederation., vol. 116, 2018, p. 422428.

[2] Tijjani, A.S., Alsabari, A.M., Sambo, Y.A., Shehu, M.A., Performance analysis for coupled - tank system liquid level control using MPC, PI and PI-plus-Feedforward Control Scheme, The Scientific Journal of Robotics, vol. 1, no. 1, 2017, p. 42-53.

[3] Venkatesh, S., Warier, S.R., Ramkumar, K., Amirtharajan, R., Model identification and predictive controller design for a nonlinear process, Research Journal of Technology, vol. 6, no. 3, 2014, p. 178-187.

[4] Ranjan, S.M., Bidyadhar, S., PI Controller design for a coupled tank system using LMI approach: An experimental study, Journal of Chemical Engineering and Process Technology, vol. 7, no. 1, 2015, p.1-8.

[5] Banerjee, S., Performance comparison between single and amp; couple rectangular tank system using NNPID controller, International Journal of Engineering and Computer Science, vol. 4, no. 9, 2015, p. 14172-14181.

[6] Belikov, J., Petlenkov, E., Model based control of a water tank system, The Proceeding of the XIX-th World Congress The International Federation of Automatic Control Cape Town, South Africa, August 24-29, 2014, p. 10838-10843.

[7] Deka, N., Mathew, L., PID controller for two tank liquid level process using LabVIEW, International Journal of Engineering Science and Computing, vol. 7, no. 5, 2017, p. 11287-11290. 
[8] Shengduo, L., Xiaolong, X., Design of liquid level control system based on PLC, Proceeding of the II-th International Symposium on Mechatronics and Industrial Informatics (ISMII 2017), 2017, p. 415-424.

[9] Elmonem, S.A.,. Mahmoud, M.M.A, Design of Tunned PID Controller for 2-Tank System, International Journal of Innovative Research in Science, Engineering and Technology, vol. 3, no. 11, 2014, p. 17124-17129.

[10] Rahmat, M.F., Rozali., S. M., Modeling and controller design for a coupled-tank liquid level system: analysis and comparison, Journal. Teknologi Universiti Teknologi. Malaysia, vol. 48, no. D, 2008, p. 113-141.

[11] Davis, I., Jishnu, C.P., William, R., Krishnan, S., Sumith, K., Sathyan, M. K. N, Level Control of two conical tank non interacting system using PID and Fuzzy Logic, International Journal of Innovative Research in Electrical, Electronics, Instrumentation and Control Engineering, vol. 5, no. 4, 2017, p. 35-42.

[12] Nagammai, S., Latha, S., Design of optimal controllers for a three tank proces, Journal of Scientific and Innovative Research, vol. 5, no. 2, 2016, p. 65-70.

[13] Nasser, H. Z., Ramli, M., Cascade control strategies for interacting tanks in series, International Journal of Engineering Sciences and Research Technology, vol. 6, no. 3, 2017, p. 21-28.

[14] Changel, M., Kumar, A., Designing a controller for two tank interacting system, International Journal of Science and Research., vol. 4, no. 5, 2015, p. 589-593. 